\title{
如何提升天气预报和气候预测的准确性
}

\author{
李丹 ${ }^{1}$ 焚希涁 $^{2}$ \\ 1 东港市气象局 2 丹东市气象局 \\ DOI:10.32629/as.v1i3.1477
}

[摘 要] 随着科学技术的发展, 我国气象部门逐渐对自动观测站进行了大范围推广应用。但是, 随着近年来, 人类生存和经济活 动导致的自然环境污染现象无法得到有效抑制,气象灾害的发生越来越频繁。因此,预防工作的有效性应基于天气和气候预报 的准确性。在实际的天气预报和气候预测时,其准确性如果出现偏差,会给人类生活和生产活动带来极大的不便性。本文对提 升天气预报和气候预测准确性的意义进行了简述,并研究了影响预测的因素,提出提升预测准确性的对策。

[关键词] 天气预报; 气候预测; 准确性

气候和天气的预测, 是关乎人类日常出行的民生大事。 当前, 受全球人类生产和生活活动影响, 全球气候变暖现象 突出, 同时灾害性天气的出现频率明显。灾害性天气, 例如: 大风、大雾、暴雨、霜冻、冰雨等, 对工农业和交通运输等 人类生产活动造成的损失巨大。同时这类灾害性天气具有突 发性。在气象工作环节, 对于突发性天气和气候的监测、预 报具有明显的准确性缺失特征。这种准确性缺失, 同时也反 映在普通气象气候的预测上。

\section{1 提升天气预报和气候预测准确性的意义}

提升天气预报和气候预测准确性, 为人们生存和生产活 动提供了天气环境预测支持。例如: 天气预报给人们出行提 供了便利, 人们根据天气预报提前了解天气变化情况, 可及 时增减衣物、带好伞具、做好防晒等; 气候预报可使从事工 农业、交通运输业等与气候有关行业, 提前做好不良天气防 范措施, 减少自然灾害影响, 减少安全事故的发生。同时, 人 们根据准确的天气预报和气候预测进行合理、科学的预防性 工作, 避免了灾害破坏。另外, 天气预报和气候预测工作的准 确性, 可促进人与自然关系的研究和缓和。

\section{2 影响天气预报和气候预测准确性的因素分析}

2.1 综合业务人员的业务能力

在我国气象部门, 预报业务技术体系建设较为不完善。 表现为: 人员专业技术能力普遍偏低, 专业预报人员圆乏。 这种现状严重影响着基层气象预报工作的精细化发展。同时 表现为: 监测站技术研发滞后, 基层人员都缺乏全面的理论 基础, 订正预报服务技术水平不高。这些原因促使天气预报 和气候预测工作的准确性无法得到保证。

\section{2 观测数据综合质量控制和管理}

气象观测数据过程, 需要经过气象要素数据采集、读 取、传输、编码及解码流程, 在每个流程中, 数据均可能出 现偏差 ${ }^{[1]}$ 。综合质量控制工作如果不能贯穿气象观测数据全 程, 就将影响天气预报和气候预测的准确性。现实中, 质量控 制系统的应用还并不普及, 同时系统功能和使用性能还有待 完善。对于各个环节的内在质量控制也需进一步提高。另外, 气象质量管理体系不健全, 也将影响数据的准确性。例如:
气象相关制度和规章不完善, 人员工作流程可能出现偏差, 进而导致天气预报和气候预测准确性; 组织机制不健全, 对 基层人员专业技术要求不高, 也是直接导致气象报告出现失 误的原因。

\section{3 城市发展压力和气象要素的复杂关系}

气象法规定, 气象观测站周边环境需地域宽阔。这项规 定说明了气象站建立需满足的环境条件要求, 这是关乎气象 观测数据信息准确, 预报天气和预测气候精确的必要条件。 然而, 随着人类生产和生活需求的增加, 城市扩张趋势明显, 城市建设越来越靠近气象站点。这种发展行为必然对气象站 周边环境产生了一定的破坏性, 在一定程度上, 造成了气象 监测环境失真现象频发。一旦气象站迁址, 区域性预报预测 资料的连续性和完整性将被打破, 严重影响了天气预报和气 候预测的准确性。

同时, 气象要素多样化, 且要素关系十分复杂。目前, 气 象研究范围内主要的气象要素包括: 气压、气温、相对湿度、 降水、风向、风速、云量、蒸发、辐射、日照、能见度等。 这些要素存在着复杂的关联性, 而气象预报预测则是要整合 一切气象要素, 进行数据分析处理的工作。如果在实际监测 过程中, 其中一项气象要素数据不准, 将影响整个天气预报 和气候预测的准确性。另外,一些特殊气象要素, 例如: 相当 温度、位温、空气密度等 ${ }^{[2]}$, 以现有的气象技术来说, 这些要 素目前无法测定, 只能通过函数求算而得。气象要素的测定 和计算的难度较大, 这也是影响天气预报和气候预测准确性 的重要因素。

\section{3 提升天气预报和气候预测准确性的对策}

3. 1 提高天气预报和气候预测的业务能力

要提高天气预报和气候预测的业务能力, 首先, 抓住准 确性这一气象预测预报的核心指标, 同时对气象预测预报的 针对性和气候影响评定量化水平进行同步提升。其次, 使常 规天气预报向精细化推进的同时, 应提升气候预测能力, 推 进平均态气候趋势预测向异常气候、极端气候趋势预测延 伸。提高气象预测预报的专业性, 在专业能力上的提升空间 范围包括: 航空、农业、海洋、水文、电力、交通、环境、 
大气环境潜势预报、流域面雨量预报、风能太阳能预报、山 洪地质灾害气象预报等气象预报预测业务能力。

\section{2 提高气象观测数据质量控制}

随着社会经济的发展, 我国气象局建设事业业务发展极 快。目前, 我国已有近 2500 个地面气象观测站。要提升气象 预测预报的准确性, 对策之一是要提高气象观测数据质量控 制。随着信息技术的发展, 关于地面气象观测数据质量控制, 实现了全面软件监控管理。在软件监控下, 可应用如下方法 进行气象观测数据的质量控制:

\section{3 极值检查}

极值检查包括: 历史极值检查和文件中极值检查。地理 条件和季节变化使检查要素值存在波动性, 极值检查就是要 观测要素的最大值和最小值以及极大值, 作为气象数据信息 参考依据。

\section{4 要素一致性检查}

要素一致性检查包括: 内部一致性检查和时间一致性检 查。根据地域、时间和物理特征气象要素, 进行气象数据检 查工作。具体方法包括: 综合一致性数据质量控制方法。这 种方法通过时间和空间一致性检查, 在一定程度上提高了气 象数据质量控制效果。其中, 这种方法涉及的主要要素包括: 气温、降水和日照时数, 通过综合一致性检查, 确定数据质量 状况 ${ }^{[3]}$ 。

3.5 提高天气预报和气候预测的技巧

科学合理的技巧方法的应用, 是提高天气预报和气候预 测准确性的有效对策之一。现行应用比较广泛的技巧方法包 括: 经验统计学方法和动力学分析方法。其中, 经验统计学 方法是根据概率学和统计学衍生的方法理论, 通过对气象要
素复杂关系的研究和分析, 观察要素间的系数变化, 进而预 测预报气候和天气。

另外, 动力学分析方法在天气预报和气候预测过程中的 应用包括: 其一, 低温热动力学研究。这种方法总结了一套 预报方程, 通过地气系统热平衡、大气水分平衡等要素进行 方程推到, 最终建立了长期预测降水量方程结果。其二, 月动 力延伸预报。它是利用 T4219 中期数值产品进行的一种月尺 度延伸预报方法。可见, 气象部门亟待发现更多的影响气象 的要素, 并对已知的气象要素进行不断地研究和分析工作, 在技术上进行不断地更新, 以期使预报预测方法在短期气候 预测和极端天气预报方面发挥重要作用。

\section{4 结束语}

目前, 气候预测在提升天气预报和气候预测的准确性上, 存在着明显的气象监测数据质量水平偏低现象, 保持气象预 测精确度成为技术难点。这就要求在气象管理上, 人员应遵 循各项制度规范和技术要求, 同时对气象质量控制工作进行 严格把关, 深入研究并分析气候变化规律特征, 在此基础上, 采取多元的技术措施对天气预报和气候预测准确性的提升 进行有效的战略部署。

[参考文献]

[1]刘艳,郭园.关于提高天气预报准确率的分析[J].黑龙 江科技信息,2015,15(20):19.

[2]高杰.如何有效提升天气预报准确性 [J].北京农 业,2016,15(5):140-141。

[3]张奎东,杨雷,陈铁,等.提高天气预报和气候预测的技 巧[J].吉林农业,2017,19(13):106. 